\title{
Smallholder Farmer's Willingness To Pay For Improved Irrigation Water Supply In Mashonaland Central Irrigation Schemes, Zimbabwe
}

\author{
Innocent Vomitadyo* Tererai Katema Tafireyi Chamboko \\ Department of Agricultural Economics and Extension; University of Zimbabwe; P.O. Box MP167; Mount
}

Pleasant; Harare; Zimbabwe.

\begin{abstract}
* E-mail of the corresponding author: vomitadyo@gmail.com

Irrigation agriculture is playing a major role in attaining food self-sufficiency and overall agricultural development in many developing countries and its development is key in promoting rural development. Due to limited capacity by governments support these schemes in most developing countries, it is important that farmers are willing to assist in recovering the cost of the management, maintenance, and operation of the irrigation system. This study therefore estimated the determinants of smallholder farmers' willingness to pay for improved irrigation water using an Ordered Probit Model. It was done in Negomo and Chimhanda irrigation schemes in Zimbabwe. Primary data was collected from 120 randomly selected smallholder farm households through a structured questionnaire and focus group discussions. The study identified Household size, household income, farmer's satisfaction with the current management practices and amount of the initial bid factors significantly influencing farmers' WTP for improved irrigation water. The study recommended that management practices and scheme operations should be oriented. management team or committee in the irrigation scheme should come up payment plans to finance system upgrade and covering maintenance cost and need to develop water management policies like water optimum prices and promote water-efficient technologies.
\end{abstract}

Keywords: Willingness to pay, Contingent valuation method, Irrigation water

DOI: $10.7176 / \mathrm{JESD} / 12-20-06$

Publication date:October $31^{\text {st }} 2021$

\section{Introduction}

Irrigation through large and small-scale water projects is playing a major role in attaining food self-sufficiency and overall agricultural development in many developing countries in recent decades. Irrigation development is also regarded as a means of increasing food, raw material production as well as promoting rural development through food security, protection against adverse drought conditions, increased prospects for employment and stable income, greater opportunity for multiple cropping and crop diversification (Manyeruke et al. 2013). Globally, smallholder irrigation systems are regarded as important common property resources that are needed to increase crop water supply and sustain livelihoods in semi-arid regions (FAO \& WWC 2015).

However, it has been argued that institutional weaknesses and performance inefficiencies of public irrigation agencies have led to high costs of development and operation of irrigation schemes in many countries (Gyasi et al. 2006 in Alemayehu 2014). This has resulted in poor maintenance and lack of effective control over irrigation practices, which consequently led to collapse of many irrigation schemes in many countries particularly in the subSaharan region (Nhundu et al. 2015). Given the limited capacity for maintenance support of most governments in Sub-Sahara particularly Zimbabwe, sustainable development and operation of these schemes require that farmers are willing to pay for operation and maintenance cost.

Despite several attempts to promote irrigation agriculture to mitigate climate change effects, in 2014 the USAID in its report, Zimbabwe Food Security Brief, reported that Irrigation has declined over the past 15 years, but has the potential to increase agricultural production. Although there are significant perennial water sources and dams in the country, the decline is primarily due to poor maintenance or damaged infrastructure, and lack of new investment. Moreover, past experience shows the limited capacity of the government for maintenance support. This has jeopardized the sustainable delivery of water services, inefficient water use practices and lack of incentives to irrigation maintenances. This has also made it difficult, in some cases incapable of sustaining water needs of the farmers and resulted low agricultural productivity.

Knowing of all concern and facts, the government is now planning different activities and measures to improve the irrigation system of Zimbabwe. However, implementing these measures require that farmers are willing to assist in recovering the cost of the management, maintenance and operation of the irrigation system that will result 
from the improvement. This show, the need of examining farmers' Willingness to Pay (WTP) for improved irrigation water services assuming the irrigation system is improved. So far, little is known about whether farmers in Zimbabwe indeed have a positive WTP, and of what size the WTP would be in different environmental goods and services. Hence, the major objective of this study was to identify the determinants of smallholder farmers' WTP for improved irrigation water services in the case of Mashonaland central irrigation scheme, Zimbabwe.

\section{Methodology}

\subsection{Study area}

This study was done in some irrigation schemes of Mashonaland Central Province of Zimbabwe. This area was chosen because of the numerous irrigation schemes in it. A large part of the province receives very little rainfall and irrigation schemes are playing a pivotal role in ensuring food security. Data was collected from farmers from Negomo and Chimhanda irrigation schemes. These schemes have been purposively chosen because they are the largest in the province in terms of number of farmers in them. Negomo irrigation scheme is in Mazowe district and has a total of 280 farmers. The region is in natural region III and the average rainfall is between $650 \mathrm{~mm}$ to $750 \mathrm{~mm}$ per annum. Chimhanda irrigation scheme is in Rushinga district and has a total of 160 farmers. The region is natural region IV and receives about $450 \mathrm{~mm}$ to $650 \mathrm{~mm}$ of rainfall per annum. Due to the increasing effects of climate change, more households are becoming reliant on these schemes for food.

\subsection{Sampling and data collection}

From the selected two irrigation schemes in the province, 120 respondents were selected using simple random sampling technique. 50 respondents were selected from Negomo irrigation scheme, and 70 respondents were samples from Chimhanda irrigation scheme. The sampling frame of farmers in these irrigation schemes was obtained from the extension officers and respective lead farmers. The required data was obtained from primary source. The primary data was collected using a pre-tested questionnaire in face-to-face interviews. Only the household heads were interviewed and taken as the farmers themselves.

\subsection{Model Estimation of Factors Affecting WTP}

The decision of the farmer to accept or reject the initial bid depends on his or her utility derived from the different scenarios presented. Hence, it can be described using a utility framework, (Hanemann 1994). Utility or satisfaction function of the respondent can be expressed as:

$$
U_{i}=U_{i}\left(Y, M, q^{j}\right)
$$

where, $U_{i}$ is the utility of respondent $i, Y$ is respondent income, $M$ is the vector of farmer's characteristics and other exogenous factors that affect his/her WTP and $q^{j}$ is the situation of the project as perceived by the respondent. The farmer will be willing to pay if he/she thinks that he/she will be better off in the proposed scenario, that is

$$
U_{i}^{1}\left(Y-B I D, M, q^{1}\right)+e_{1} \geq U_{i}^{0}\left(Y, M, q^{0}\right)+e_{0}
$$

where $U_{i}^{1}$ and $U_{i}^{0}$ are the farmer utility derived from the improved situation and the original situations of the project, respectively, and $B I D$ is the initial amount of money proposed to the respondent, and the other variables are as defined above.

The study employed a double bounded dichotomous elicitation format which starts by asking whether a farmer is willing to pay a pre-specified initial bid $t$ or not. If he/she answers "no" to the pre-specified initial bid, he/she is offered a lower bid value $t^{L}$ and if the respondent answers "yes" to the initial bid, he/she receives a higher bid $t^{H}$. This gives four possible ordered outcomes for the willingness to pay responses:

$$
\begin{array}{ll}
W T P \geq t^{H} & \text { for yes - yes response, } \\
t \leq W T P \leq t^{H} & \text { for yes-no response, } \\
t^{L} \leq W T P \leq t & \text { for no-yes response, } \\
W T P \leq t^{L} & \text { for no-no responses }
\end{array}
$$


By applying a latent variable framework, the function can be specified as

$$
y^{*}=x^{\prime} \beta+u
$$

where $y^{*}$ is the unobservable true utility of the respondent, $\beta_{i}$ is the vector of parameters to be estimated, $X_{i}$ is the vector of explanatory variables, $u$ is an error term which, in this case, is assumed to follow a normal distribution and the utility function. Thus, the depended variable takes the following values:

$$
y=\left\{\begin{array}{l}
0, \text { if } y^{*} \leq \alpha_{1} \\
1, \text { if } \alpha_{1}<y^{*} \leq \alpha_{2} \\
2, \text { if } \alpha_{2}<y^{*} \leq \alpha_{3} \\
3, \text { if } y^{*}>\alpha_{3}
\end{array}\right.
$$

where $\alpha_{1}, \alpha_{2}$ and $\alpha_{3}$ are the cut off points. Since the depended variable had four categories and ordinal, an Ordered Probit Model was appropriate (Liddell \& Kruschke 2018). It takes the form

$$
\boldsymbol{y}=\boldsymbol{x}^{\prime} \boldsymbol{\beta}+\boldsymbol{u}
$$

with probabilities of different categories given as follows:

$$
\begin{aligned}
& \operatorname{Pr}(y=0 \mid x, \beta)=F\left(\alpha_{1}-x^{\prime} \beta\right) \\
& \operatorname{Pr}(y=1 \mid x, \beta)=F\left(\alpha_{2}-x^{\prime} \beta\right)-F\left(\alpha_{1}-x^{\prime} \beta\right) \\
& \operatorname{Pr}(y=2 \mid x, \beta)=F\left(\alpha_{3}-x^{\prime} \beta\right)-F\left(\alpha_{2}-x^{\prime} \beta\right) \\
& \operatorname{Pr}(y=3 \mid x, \beta)=1-F\left(\alpha_{3}-x^{\prime} \beta\right)
\end{aligned}
$$

The explanatory variables are total household income, age in completed years, marital status ( 1 for currently married, 0 otherwise), education level ( 1 for beyond secondary level, 0 for otherwise) household size, Tropical Livestock Unit (TLU), household income in USD, current price of water per 0.5 ha per month, farmer's satisfaction with the management practices ( 1 for satisfied, 0 for otherwise) and the initial bid in USD.

\section{Results and Discussion}

\subsection{Characterisation of sampled households}

Table 1 shows the mean and standard deviation of age, household size, TLU and household income of respondents in the two sampled irrigation schemes. At 5\% significance level the independent $t$ test showed that the mean household income of farmers in Negomo (\$3137.91) was significantly higher than that of farmers in Chimhanda (\$1562.49). The means of age, household size and TLU of farmers in Chimhanda were not significantly different from those of farmers in Negomo irrigation scheme. The mean age of the whole sample was 47.4 years. This means that there were few youths in the sampled respondents. Their mean household income was US\$2197.95 per annum.

Table 1: Mean and Standard deviation for age, household size, tropical livestock unit and income

\begin{tabular}{|l|l|c|c|c|c|}
\hline Irrigation Scheme & Statistic & Age of Farmer & Household Size & TLU & Household income \\
\hline Chimhanda & Mean & 47.52 & 5.33 & 2.76 & 1562.493 \\
\cline { 2 - 6 } & Std. Deviation & 14.09 & 2.14 & 2.38 & 2024.857 \\
\hline \multirow{2}{*}{ Negomo } & Mean & 47.23 & 5.27 & 2.87 & 3137.917 \\
\cline { 2 - 6 } & Std. Deviation & 13.73 & 2.35 & 3.45 & 3340.771 \\
\hline \multirow{2}{*}{ Total } & Mean & 47.40 & 5.30 & 2.80 & 2197.958 \\
\cline { 2 - 6 } & Std. Deviation & 13.89 & 2.22 & 2.83 & 2734.956 \\
\hline
\end{tabular}


Respondents also gave responses that fit in four categories depending on their responses to the first and second bids as shown in figure 1 . About $60.8 \%$ of the participants answered yes to the initial bid than those who answered no. This means that more people were willing to pay the initial bid. Some socio-economic parameters such as gender, marital status, education, and Tropical livestock Unit were not significantly different among households who gave these four categories of responses. Results also show that the average Tropical Livestock Unit of livestock owned was 2.80 per household.

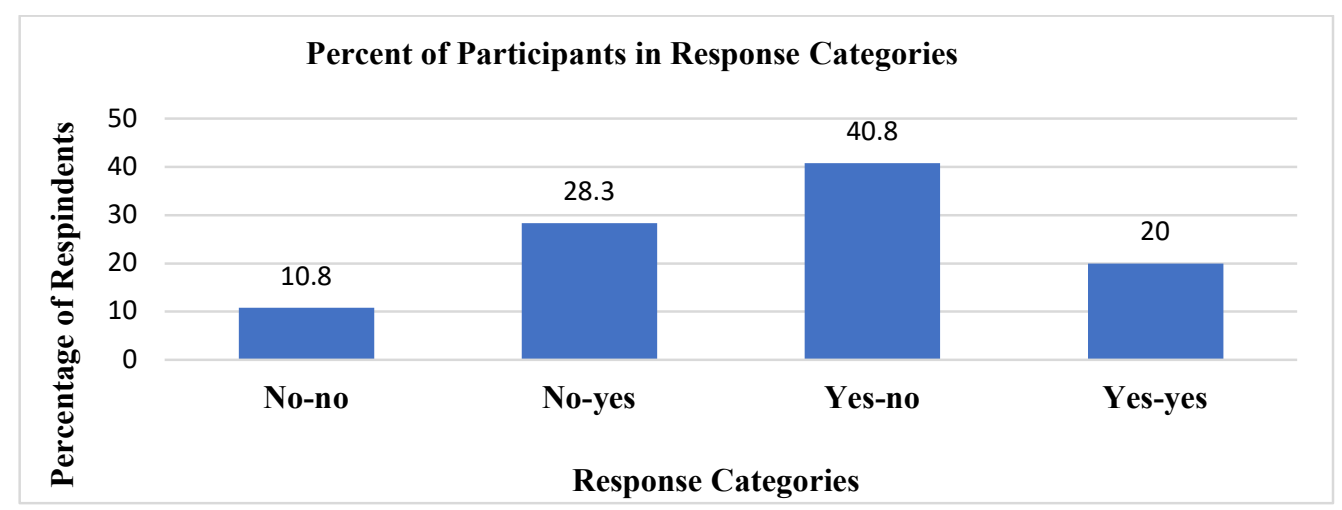

Figure 1: Mean income for respondents in different categories of responses

The Ordered Probit model with eight predictors was statistically significant $(F=60.9, \rho=0.0003)$. Out of nine explanatory variables included in the model, four were significantly influencing farmers WTP. These were family size, household income, farmer's satisfaction with the current management practices and amount of the initial bid. Household size and income had a negative effect on the farmers' WTP for the improved irrigation water services. Initial bid and satisfaction had a positive influence on farmers' WTP. However, the rest of the explanatory variables included in the model were not significant at 10\% level. Table 3 shows the results of the Ordered Probit Regression Model of the determinants of WTP responses by smallholder farmers.

Table 3: Ordered Probit regression results for determinants of WTP

\begin{tabular}{|c|c|c|c|c|c|c|c|}
\hline \multirow[t]{2}{*}{ Variable } & \multirow[t]{2}{*}{ Coefficient } & \multirow[t]{2}{*}{ Std Errors } & \multirow[t]{2}{*}{ P-Value } & \multicolumn{4}{|c|}{ Marginal Effect (0) } \\
\hline & & & & $P(Y=0)$ & $P(Y=1)$ & $P(Y=2)$ & $P(Y=3)$ \\
\hline Age & 0.0007455 & 0.0007455 & 0.732 & -0.00044 & -0.00062 & 0.00032 & 0.00074 \\
\hline Marital status & -0.0393309 & -0.0393309 & 0.347 & 0.02369 & 0.03290 & -0.01726 & -0.03933 \\
\hline Education & 0.0032126 & 0.0032126 & 0.923 & -0.00193 & -0.00268 & 0.00141 & 0.00321 \\
\hline Household size & $-0.0211385^{*}$ & -0.0211385 & 0.092 & 0.01273 & 0.01768 & -0.0092 & -0.02113 \\
\hline TLU & -0.0130698 & -0.0130698 & 0.173 & 0.00787 & 0.01093 & -0.00573 & -0.01306 \\
\hline Household income & $-0.0000201^{*}$ & -0.0000201 & 0.075 & 0.00001 & 0.00001 & -0.000008 & -0.00002 \\
\hline Price of water & 0.0104848 & 0.0104848 & 0.337 & -0.00631 & -0.00877 & 0.00460 & 0.01048 \\
\hline Satisfaction & $0.0962351 *$ & 0.0962351 & 0.096 & -0.06127 & -0.08065 & 0.04569 & 0.09623 \\
\hline Initial bid & $-0.040232 * * *$ & 0.040232 & 0.000 & 0.02424 & 0.03365 & -0.01766 & -0.0402 \\
\hline $\begin{array}{l}\text { /cut1 } \\
\text { /cut2 } \\
\text { /cut3 }\end{array}$ & & $\begin{array}{l}-1.238993 \\
-0.2923137 \\
1.116799\end{array}$ & & & & & \\
\hline
\end{tabular}

*** Significant at 1\% level, ** Significant at 5\% level, * Significant at 10\% level 
Household size of the respondent was negative and significant at $10 \%$ significance level $(p=0.093)$. This implies that households of large numbers of family members were more willing to pay higher bids as compared to households with small numbers of family members. Their willingness to pay was low. This is probably because these households have a large number of dependants. This raises their consumption levels as a result they are little money left for investments. These findings were contrary to the findings of Chandrasekaran et al. (2009) and Martin-Ortega et al. (2012). The marginal effect of -0.02113 in the category $\mathrm{P}(\mathrm{Y}=3)$ shows that, keeping all other things constant at their mean, an increase in household size by one member reduces the probability that an individual will be willing to pay more than the highest bid proposed by $2.1 \%$

The total income of the respondents had negative and significant effects at $10 \%$ significance level $(\beta=-0.0000201$, $\rho=0.075)$. This relationship indicates that higher income households have a lower WTP than lower income households. This result contradicts the general demand theory which states that there is a positive relationship between income and demand for goods. This is probably because higher income households have more confidence that they can use their own resources during the times of water shortages. However, the marginal effects of 0.00001 and -0.00002 shows that the probabilities will only change by a very small margin $(0.001 \%$ and 0.002$)$. Different results have been obtained by Balana (2013), Arouna \& Dabbert (2012), Tessema et al. (2013) and Chandrasekaran et al. (2009) who also conducted a CVM study on irrigation water.

The coefficient of initial bid proposed was negative and significant at $1 \%$ level of significance. This is consistent with a priori expectation as well as with the economic theory of the negative relationship that exists between price and demand of a good. The negative sign implied that as the bid offered to the respondent increased the probability of household WTP for the improved water service decreased. The results are also in agreement with the study done on improved water service in Harare town by Coster \& Otufale (2014). They recognized a negative relationship between willingness to pay and initial bid. The marginal effects of the initial bid in the last category of -0.0402 indicated that a one dollar increase in the bid price proposed would decrease the probability of the farmer to pay amount greater than the higher bid by $4 \%$. The results also suggest that more farmers would be willing and afford to pay for the improvement if the proposed bid is reduced.

The coefficient farmer's satisfaction with the management was positive and it was significant at $1 \%$ level of significance $(\beta=0.0962351$ and $\rho=0.096)$. This is different with a-priori expectation. The positive sign means that farmers who are satisfied with current management practices are more willing to pay for improved irrigation water service than those who are not satisfied. The marginal effect of 0.09623 in the $\mathrm{P}(\mathrm{Y}=3)$ category means that farmers who are satisfied have a probability of paying for the highest bid which is higher by $9.6 \%$ than that of farmers who were not satisfied. This is probably because farmers who are satisfied with that management practices have more confidence that they will get what they are paying for. Farmers are willing to invest in a more robust system.

\section{Conclusion}

Determinants of Willingness to pay for improved irrigation water service were estimated using an Ordered Probit Model. Household size, household income, farmer's satisfaction with the current management practices and the initial bid were found to be the factors significantly influencing farmer's willingness to pay for improved irrigation water service. Household size, household income and initial bid negatively influences household willingness to pay for improved irrigation water service and farmer's satisfaction have a positive effect on WTP. Due to the positive effect of farmer's satisfaction on the farmer's WTP for improvement, management practices and scheme operations should be demand driven or oriented. This will increase farmer's WTP and hence lead to a sustainable improvement.

\section{References}

Balana, B. (2013). Assessing the willingness to pay for reliable domestic water supply via catchment management: results from a contingent valuation survey in Nairobi City, Kenya. Journal of Environmental Planning and Management 56(10): 1511-1531 doi.org/10.1080/09640568.2012.732934

Manyeruke, C., Hamauswa, S., \& Mhandara, L. (2013). The Effects of Climate Change and Variability on Food Security in Zimbabwe: A Socio-Economic and Political Analysis. International Journal of Humanities and Social Science 3(6). 
Coster A. S., \& Otufale G. A. (2014). Households' Water-Use Demand and Willingness to Pay for Improved Water Services in Ijebu Ode Local Government Area, Ogun State, Nigeria. Journal of Environmental Earth Sciences. 4(17), 2225-0948.

FAO., \& WWC. (2015). Towards a water and food secure future: Critical perspectives for policymakers. White paper. Rome: Food and Agriculture Organization of the United Nations and Marseille: World Water Council.

Hanemann, W. M. (1994). "Valuing the environment through contingent valuation." The Journal of Economic Perspectives: 19-43.

K. Nhundu, A. Mushunje, L. Zhou and F. Aghdasi. (2015). Institutional determinants of farmer participation in irrigation development post "fast-track" land reform program in Zimbabwe. Journal of Agricultural Biotechnology and Sustainable Development. ISSN 1996-0816 Vol. 7(2), pp. 9-18.

Tesfahun Alemayehu. 2014. Smallholder Farmer's Willingness to Pay for Improved Irrigation Water: A Contingent Valuation Study in Koga Irrigation Project, Ethiopia. Journal of Economics and Sustainable Development, ISSN 2222-1700 (Paper) ISSN 2222-2855 Vol 5, No.19.

Liddell, T., \& Kruschke, J (2018). Analyzing ordinal data with metric models: What could possibly go wrong? Journal of Experimental Social Psychology. 79: 328-348. doi:10.1016/j.jesp.2018.08.009

Chandrasekaran, K., Devarajulu, S., \& Kuppannan. P., (2009). Farmers' Willingness to Pay for Irrigation Water: A Case of Tank Irrigation Systems in South India. Water. 1(1), 5-18. 10.3390/w1010005.

Martin-Ortega, J., \& Ojea, E., \& Roux, C., (2013). Payments for Water Ecosystem Services in Latin America: A literature review and conceptual model. Ecosystem Services. 6. 10.1016/j.ecoser.2013.09.008.

Arouna, A., \& Dabbert, S., (2012). Estimating rural households' willingness to pay for water supply improvements: A Benin case study using a Semi-Nonparametric Bivariate Probit Approach. Water International. 37. $293-304$. $10.1080 / 02508060.2012 .687507$.

Tessema, Y. A., Aweke, S., \& Getachew, S., (2013). Understanding the process of adaptation to climate change by small-holder farmers: the case of east Hararghe Zone, Ethiopia. Agricultural and Food Economics. 1. 13. 10.1186/2193-7532-1-13. 